\title{
Proteomics characterization of primary human oral epithelial cells using a novel culture technique for use in tissue regeneration
}

\begin{abstract}
Oral mucosa keratinocytes are widely used in regenerative medicine. The unique cultured cell population "Epithelial-derived Pop-Up Keratinocytes (ePUKs)" was previously reported as undifferentiated cells. Gravity Assisted Cell Sorting (GACS) was used to isolate a small-sized population of undifferentiated cells enriched ePUKs.LC/MS/MS analysis was performed to define the cellular profile of ePUKs of primary human oral mucosa keratinocytes. Small sized ePUKs which showed increased expression of Dickkopf WNT signaling pathway inhibitor 1 (DKK1), serpin peptidase inhibitor, clade E (nexin, plasminogen activator inhibitor type 1), member 1 (SERPINE1), follistatin and tenascinCrewe verified by Western blots. These proteins are involved in the regulation of cellular movement, hair follicle development and the maintenance of its stem cell niche. The fabrication of a tissue-engineered oral mucosa, ex vivo produced oral mucosa equivalent (EVPOME), using ePUKs showed increased abundance of these verified proteins. These findings indicate that the specific phenotype of ePUKs and their ability to influence wound healing promotion are implicated by highly expressed cellular movement regulatory proteins. Therefore, ePUKs may be a useful cell source for us in regenerative medicine.
\end{abstract}

Keywords: oral mucosa, quantitative proteomics, tissue engineering
Volume 2 Issue 4 - 2015

\author{
Hiroko Kato, ${ }^{1,2}$ Andy Lo, ${ }^{3}$ Shiuhyang Kuo,' \\ Song Nie, ${ }^{3}$ Cynthia L Marcelo,' David M \\ Lubman, ${ }^{3}$ Stephen E Feinberg' \\ 'Department of Oral and Maxillofacial Surgery, University of \\ Michigan, USA \\ ${ }^{2}$ Department of Biomimetics, Niigata University Postgraduate \\ School of Medical and Dental Sciences, Japan \\ ${ }^{3}$ Department of Surgery, University of Michigan Medical Center, \\ USA
}

Correspondence: Stephen E Feinberg, University of Michigan Health System, Towsley Center Rm GIII4, 1515 East Medical Center Drive, Ann Arbor, MI 48109-5222, USA, Phone + 17347635963, Fax + 17347636199,

Email sefein@med.umich.edu

\begin{abstract}
Co-correspondence: David M Lubman, University of Michigan Medical Center, Department of Surgery, II 150 W. Medical Center Drive, MSRB I,A5 IOB, Ann Arbor, MI 48109-0650, USA, Phone+17346478834, Fax+17346152088, Email dmlubman@ umich.edu
\end{abstract}

Received: June 20,20I5 | Published: August 12, 2015

\begin{abstract}
Abbreviations: EVPOMEs, ex vivo produced oral mucosa equivalents; DKK1, dickkopf wnt signaling pathway inhibitor 1; ePUKs, epithelial pop-up keratinocytes; GACS, gravity assisted cell sorting; FST, follistatin; SERPINE1, serpin peptidase inhibitor, clade e (nexin, plasminogen activator inhibitor type 1), member 1; TNC, tenascin-c
\end{abstract}

\section{Introduction}

Oral mucosa keratinocytes are widely used for intraoral and extra oral clinical applications including reconstructions of cornea, urethral/bladder and esophagus. ${ }^{1}$ Rapid expansion of high quality cells is essential for decreasing the culture period resulting in prompt treatment and, mitigation of labor and cost. Therefore, a successfully isolated stem/progenitor cell would provide a robust source of cells for use in regenerative medicine. We defined "epithelial-derived PopUp Keratinocytes (ePUKs)", which is human epithelial cells having high proliferative ability using a unique culture system and expansion technique. ${ }^{2,3}$ Further characterization of ePUKs is needed prior to their tissue engineering applications. ePUKs are floating, non-attached cells produced by large sized colonies in monolayer culture which are fed daily with 2-fold the usual amount of culture medium and the cell suspension containing ePUKs is poured into a new flask to form another monolayer without the use of enzymes to split the cultures. ${ }^{2}$ Small-sized cultured keratinocytes are reported as a progenitor/stemcell-enriched population since they have a high ability of colony formation and long term proliferative capacity. ${ }^{4,5}$ However, when investigating the ePUKs undifferentiated profile, it is important to eliminate the contamination of the large sized dead or aged cells which are also floating in the media over laying a confluent mono layer, that lose their adherent ability. In our previous study, Gravity Assisted Cell Sorting (GACS) was reported as a unique method to separate cells by size. ${ }^{6}$ Isolation of small sized cells in ePUKs using this method provides us with an enriched undifferentiated smallsized cell population. We hypothesize that a comparison of selected small-sized cells in ePUKs versus traditional monolayer cultured cells would assist us in identifying specific markers, which would be useful to isolate them for clinical use. Thus, the aim of this study is to characterize small-sized ePUKs comprehensively by a proteomicsbased approach to define their usefulness in regenerative medicine.

\section{Materials and methods}

\section{Procurement of human oral mucosa}

Discarded keratinized oral mucosa was obtained from four patients; three males and one female with a mean age of 42.5 years without any malignancies, undergoing tooth extraction and/orminor den to-alveolar surgery. The protocol for harvesting human oral mucosal tissue was approved by a University of Michigan Internal Review Board.

\section{Primary oral keratinocytes and serial cultures and ePUKs culture}

As described previously with modification, ${ }^{7}$ mucosal tissue was digested overnight with $0.04 \%$ trypsin solution (Life Technologies, 
Carlsbad, CA, USA) with $19.25 \mu \mathrm{g} / \mathrm{mL}$ of gentamicin (Life Technologies) and $0.765 \mu \mathrm{g} / \mathrm{mL}$ of fungi zone (Life Technologies) at room temperature, and transferred into $0.0125 \%$ trypsin-inhibitor (Life Technologies). Dissociated oral keratinocytes were resuspended in a chemically defined culture system, complete Epilife (Life Technologies) and seeded into one T-25 flask. For serial cultures, cells were detached in $0.025 \%$ trypsin/EDTA (Life Technologies). For analysis, monolayer culture cells were fed adding $30 \mathrm{~mL}$ of Epilife $/ 150 \mathrm{~mm}$ Petri culture dish every other day and collected after detachment in Enzyme Free Cell Dissociation Solution (Millipore, Billerica, MA, USA). ePUKs culture was previously described. ${ }^{2}$ The cells were fed adding $60 \mathrm{~mL}$ of medium/ $150 \mathrm{~mm}$ Petri culture dish, every 24 hour. At confluence, the monolayer's continued to proliferate; pushing keratinocytes into the overlying medium and the cells in suspension were collected as ePUKs. The monolayer cells underlying ePUKs culture were collected after detachment in Enzyme Free Cell Dissociation Solution (Millipore).

\section{Gravity assisted cell sorting (GACS)}

Gravity Assisted Cell Sorting (GACS) was performed as previously described. ${ }^{6}$ An ethanol sterilized funnel made from Millipore Nylon net filters (pore size; 11 and $20 \mu \mathrm{m}$ ) was used to filter the cells tominimize size contamination in the small cell population. Each keratinocyte suspension was sized into two groups: cells trapped by a $20 \mu \mathrm{m}$ filter (large cells), and cells flowing through both a 20 and $11 \mu \mathrm{m}$ filter (small cells).

\section{Protein lyses and digestion}

Cell samples from one patient were lysed using RIPA buffer with proteinase inhibitor (Roche Diagnostics, Basel, Switzerland) and 10mM PMSF (Sigma-Aldrich, St Louis, MO, USA). Lysates were centrifuged at $15,000 \mathrm{~g}$ for $10 \mathrm{~min}$ at $4^{\circ} \mathrm{C}$ and supernatant was transferred to another tube. Protein concentration was measured by BCA method. $50 \mu \mathrm{g}$ of protein from each sample were reduced and alkylated in $100 \mathrm{~mm}$ ammonium bicarbonate $(\mathrm{pH} 8)$ (Sigma-Aldrich) and $0.2 \%$ SDS (Sigma-Aldrich) solution using dithiothreitol (SigmaAldrich) and iodoacetamide (Sigma-Aldrich) reagent. The protein was precipitated by adding 5volumes of cold acetone and storing the sample overnight at $-80^{\circ} \mathrm{C}$. The resultant protein pellets were resuspended in4M urea in $100 \mathrm{~mm}$ NH4HCO3 solution. An enzyme mixture of trypsin-LysC (Promega, Madison, MI, USA) was added to each sample in a 1:50 (enzyme: sample) ratio and the samples were incubated overnight at $37^{\circ} \mathrm{C}$.

\section{Sample labeling and fractionation}

The digested samples from the different cell populations were chemically labeled using amine-reactive tandem mass tags (TMT) (Thermo Fisher Scientific) following manufacturer's instructions. The labeled samples were combined and desalted using $\mathrm{C} 18$ spin columns (PolyLC, Columbia, MD, USA). The sample was fractionated using high pH RPLC on a Thermo Electron Finnegan TSQ Quantum Ultra AM HPLC with an X Bridge C18 column (2.1mm i.d. x 100mm, $5 \mu \mathrm{m}$ particle size, Waters, Milford, MA, USA). Mobile phase A was $10 \mathrm{~mm}$ ammonium formate in $\mathrm{H}_{2} \mathrm{O}(\mathrm{pH} 10)$ and mobile phase $\mathrm{B}$ was $10 \mathrm{~mm}$ ammonium formate in 10:90 $\mathrm{H}_{2} \mathrm{O}$ : acetonitrile $(\mathrm{pH} \mathrm{10)}$. A flow rate of $0.2 \mathrm{~mL} / \mathrm{min}$ was used with the following gradient program (time in $\min \%$ B): 0min, 4\%; 4.0, 4\%; 5.0, 5\%; 95.0, 50\%; 110.0, 70\%; 110.1, $90 \% ; 115.0,90 \% ; 115.1,4 \% ; 120,4 \%$. Fractions were collected every minute and pooled together into twenty fractions by concatenated fractionation (e.g., fractions from 1, 21, 41, 61, 81, and 101minutes were combined).

\section{LC/MS/MS}

The samples were analyzed by LC/MS/MS on a Proxeon EasynLC II system (Thermo Fisher Scientific) and an Orbit rap Elite mass spectrometer (Thermo Fisher Scientific). Peptides were separated at a flow rate of $400 \mathrm{NL} / \mathrm{min}$ on a $75 \mu \mathrm{m}$ i.d. x $25 \mathrm{~cm}$ column packed in-house with Magic C18 AQ $100 \AA 5 \mu \mathrm{m}$ particle size material. A $130 \mathrm{~min}$ linear gradient from 2 to $35 \%$ acetonitrile in $0.1 \%$ formic acid was used. The MS instrument was operated in positive ion mode. Survey MS scans (from $\mathrm{m} / \mathrm{z} 400-2000$ ) were acquired in the Orbit rap analyzer with resolution $\mathrm{R}=120000$ at $\mathrm{m} / \mathrm{z} 400$, and the top 20 most intense ions were selected for tandem MS analysis by HCD. The normalized collision energy was set at $35 \%$ for $\mathrm{MS} / \mathrm{MS}$.

\section{Data analysis}

All acquired MS/MS spectra were searched against a concatenated forward-reverse database generated from the Swiss-Prot Human data base(downloaded April 2013) using the Andromeda search engine implemented in Marquand (v 1.3.0.5). Searches were performed using the following settings: precursor ion $\mathrm{m} / \mathrm{z}$ tolerance: $\pm 10 \mathrm{ppm}$; MS/MS $\mathrm{m} / z$ tolerance: $\pm 20 \mathrm{ppm}$; up to two missed cleavages; static modification: carbamidomethylation $(+57.02146 \mathrm{Da}, \mathrm{C})$ and TMT 6-plex $(+219.163 \mathrm{Da})$ of lysine sand peptide N-termini; dynamic modifications: oxidation $(+15.99492 \mathrm{Da}, \mathrm{M})$ and protein $\mathrm{N}$-terminal acetylation $(+42.011 \mathrm{Da})$. Identifications were filtered using a $1 \%$ peptide-level false discovery rate (FDR) and a 1\% protein-level FDR. Quantification was performed using the intensity of TMT reporter ions.

\section{Ingenuity pathway analysis (IPA)}

In order to obtain detailed molecular information and infer significant signaling pathways from the proteome profiling results, differentially expressed proteins identified between sample ePUKs small vs. monolayer small were uploaded into the pathway analysis tool IPA (Ingenuity Systems, Redwood City, CA, USA) as previously described. ${ }^{8}$ The uploaded Excel file contains the relevant proteins with their fold change and corresponding primary accession number (Supplemental Table 4). The significance values for canonical pathways were calculated using the right tailed Fisher's Exact Test by comparing the number of proteins that were involved in a given function or pathway relative to the total number of occurrences of these proteins in all functional/ pathway annotations stored in the Ingenuity Pathway Knowledge Base (IPKB).

\section{Immunoblot}

Cells from 3 individuals were lysed using RIPA buffer previously mentioned. For follistatin (FST), Dickkopf-related protein 1 (DKK1) and PAI-1 (SERPINE1), 50 $\mu \mathrm{g}$ from monolayer small and $10 \mu \mathrm{g}$ from ePUKs small whole-cell extracts protein per lane were

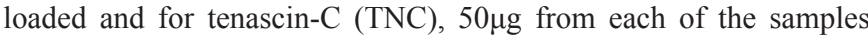
were resolved by SDS-PAGE and electrophoretically transferred to polyvinylidenedifluoride membranes. Membranes were then incubated overnight at $4{ }^{\circ} \mathrm{C}$ with 1:200 anti-FST, (Sigma-Aldrich, HPA018155), 1:200 anti-DKK1,(Santa Cruz, Santa Cruz, CA, USA,sc22516), 1:500 anti-tenascin-C (Abcam, Cambridge, MA, USA, ab108930), 1:200 anti-PAI-1,(Santa Cruz, sc5297), or 1:1000 anti- $\beta$-actin (Cell Signaling Technology, Beverly, MA, USA, \#4970) antibodies followed by 1:2000 goat-anti rabbit secondary antibody (Cell Signaling Technology, \#7074) or horse-anti mouse secondary antibody ((Cell Signaling Technology, \#7076). Signals were detected by the chemiluminescence reagent (Thermo Fisher Scientific). 


\section{Regenerative assay}

Both ePUKs and monolayer cells used to manufacture tissueengineered oral mucosa, EVPOMEs, were from the same cell strain. ePUKs were collected without centrifugation when monolayer cells reached at around $85 \%$ confluence. Monolayer cells were harvested by trypsinization and centrifugation. $1.9 \times 105$ cells of either ePUKs and monolayer cells were seeded onto $1 \mathrm{~cm}$ diameter AlloDerm ${ }^{\circledR} \mathrm{s}$ (Life Cell, Branchburg, NJ, USA) submerged in medium containing $0.06 \mathrm{mM}$ calcium for 24 hours. On the following day, the medium was switched to growth medium containing $1.2 \mathrm{mM}$ calcium for four days followed by an additional seven days in air-liquid phase. Medium was changed every day. EVPOMEs were then fixed in $10 \%$ formalin.

\section{Histological and Immuno Histochemical Characterization of Evpomes}

Formalin-fixed, paraffin-embedded (FFPE) EVPOMEs were cut into $4.5 \mu \mathrm{m}$ sections, deparaffinized, and stained with hematoxylineosin for histological examination. For immunohistochemistry, FFPEEVPOME sections underwent heat-induced antigen retrieval using a Low pH Flex flow pH 6.0 (Dako, Carpinteria, CA, USA) for 20minutes and were used after blocking endogenous peroxidase activity. The primary antibodies used were anti-FST 1:100, anti-DKK1 1:200, antiPAI-1 1:200, anti-Tenascin-C1:100, for 2hours at room temperature. For control sections, the primary antibody was omitted. The sections were incubated with Flex Rabbit/Mouse envision system horseradish peroxidase- (HRP) labelled anti-rabbit polymer (Dako) for 90minutes and visualized with DAB (Liquid DAB + Substrate SystemTM, Dako) for 2 minutes at room temperature. Sections were counter-stained with Hematoxylin.

\section{Results}

LC/MS/MS analysis of TMT-labeled peptides The study design is shown in the Graphical Abstract. Monolayer cultured (regular culture) keratinocytes, ePUKs and monolayer keratinocytes from ePUKs culture (double medium culture) were separated by size using GACS and the protein concentration of the different cell samples were determined, followed by reduction with dithiothreitol, alkylation with iodoacetamide, and digestion with a Lys-C/trypsin enzyme mixture. The digested samples were then reacted with amine-reactive TMT labels and mixed together before fractionation by high pH RPLC. The collected fractions were combined and analyzed by LC/MS/MS on an Orbit rap Elite mass spectrometer. A total of 53542 peptides and 11870 unique peptides were identified from samples analyzed on the LTQ-OrbitrapVelos. A final total of 6064 proteins were identified from samples by Max Quant. (A complete list of proteins identified in all the analyses is shown in (Supplemental Table 4).

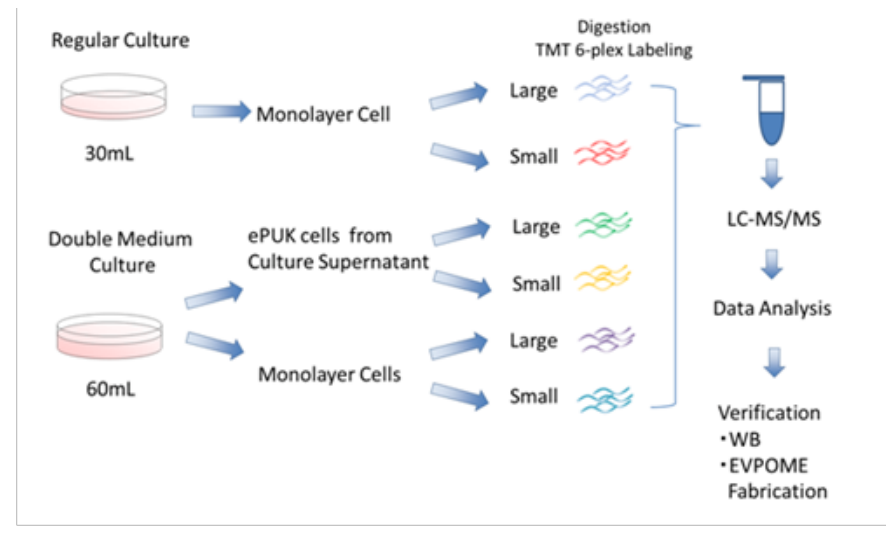

Graphical Abstract

\section{Protein Profiles}

The small-sized cells in each experimental condition which include the monolayer, ePUKs and monolayer from ePUKs culture contain an enriched population of undifferentiated cells while large-sized cells contain differentiated cells (Supplemental Table 1-5). 80\% confluences of monolayer cultured cells are generally used in experiment or clinical therapy where once they reach $100 \%$ confluence, they are committed to growth arrest due to contact inhibition (Supplemental Table 4). ${ }^{3,9,10}$ Therefore, to elucidate a specific marker genuinely characterizing ePUKs, we compared serial monolayer small cells and ePUKs smallsized cells for further analysis. The differentially expressed molecular and protein functions in ePUKs small cells versus monolayer small cells involve cell death and survival, cellular growth and proliferation, nucleic acid metabolism, small molecule biochemistry and cellular movement (Table 1).

Table I Cellular and Molecular function of ePUKs Small vs Monolayer Small Population

\begin{tabular}{lll} 
Name & p-Values & \# of Molecules \\
\hline Cell Death and Survival & $6.88 \mathrm{E}-14-1.74 \mathrm{E}-02$ & 349 \\
Cellular Growth and Proliferation & $3.10 \mathrm{E}-09-8.69-03$ & 340 \\
Nucleic Acid Metabolism & $2.63 \mathrm{E}-08-7.39 \mathrm{E}-03$ & 65 \\
Small Molecule Biochemistry & $2.63 \mathrm{E}-08-1.05 \mathrm{E}-02$ & 93 \\
Cellular Movement & I.06E-06- I.44E-02 & 187
\end{tabular}

Verification of specifically higher expression in ePUKs small population by western blot and regenerative assay

We selected four proteins from the group that showed more than threefold difference between ePUKs small cells versus monolayer small cells and monolayer from ePUKs culture small cells from same cell strain (Table 2), (Supplemental Table $2 \& 4$ ). These proteins are all involved in cellular movement (Figure 1). DKK1, SERPINE1, FST, and TNC expression were validated by Western blot and intense expressions of those proteins were seen in ePUKs small cells (Figure 2 ). The regenerative ability of the monolayer cells and ePUKs cells was investigated by fabricating tissue-engineered oral mucosa, EVPOMEs. Both showed well stratified epithelium in H-E staining (Figure $3 \mathrm{a} \& 3 \mathrm{~b}$ ). Immunohistochemical analysis revealed the increased expression of DKK1, SERPINE1 and follistatin in ePUKs EVPOMEs (Figure 3c-3h), while tenascin-C expression was similar between both cell populations (Figure 3i-3j).

Table 2 Differentially Expressed Proteins in ePUKs Small Population for Verification

\begin{tabular}{|c|c|c|c|c|}
\hline Symbol & Entrez gene name & $\begin{array}{l}\text { Fold } \\
\text { change } \\
\text { location }\end{array}$ & Location & Types \\
\hline DKKI & $\begin{array}{l}\text { Dickkopf WNT } \\
\text { signaling pathway } \\
\text { inhibitor I }\end{array}$ & 14.64 & $\begin{array}{l}\text { Extracellular } \\
\text { Space }\end{array}$ & $\begin{array}{l}\text { Growth } \\
\text { Factor }\end{array}$ \\
\hline SERPINE & $\begin{array}{l}\text { Serpin peptidase } \\
\text { inhibitor, clade } \\
E((\text { nexin, plasminogen } \\
\text { activator inhibitor } \\
\text { type I) }\end{array}$ & 12.849 & $\begin{array}{l}\text { Extracellular } \\
\text { Space }\end{array}$ & other \\
\hline FST & Follistatin & 10.425 & $\begin{array}{l}\text { Extracellular } \\
\text { Space }\end{array}$ & other \\
\hline TNC & tenascin & 4.328 & $\begin{array}{l}\text { Extracellular } \\
\text { Space }\end{array}$ & other \\
\hline
\end{tabular}




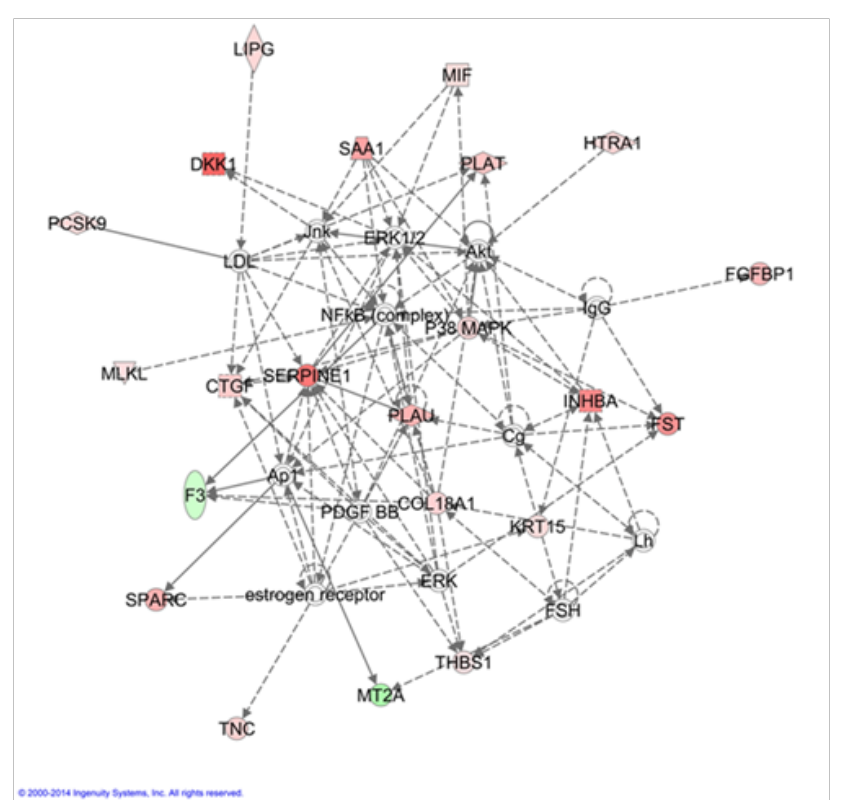

Figure I Molecular network of Cellular Movement constructed by IPA. Red and green represent over- and under-expression in small-sized ePUK compared with monolayer small-sized cell population, respectively.

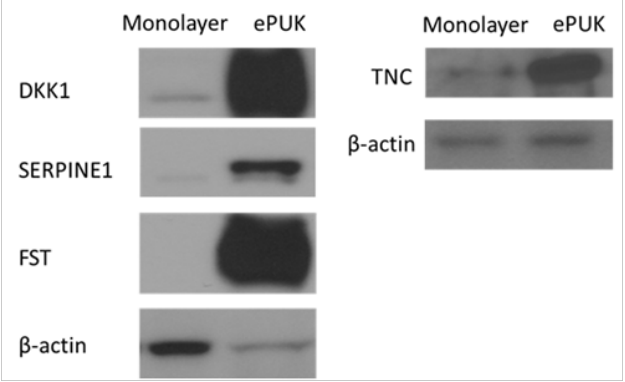

Figure 2 Verification of the protein expression between ePUK small and monolayer small population identified by LC/MS/MS. FST, DKK-I, SERPINEI and TNC expression were validated by Western blot. $\beta$ - Actin is shown as loading control.

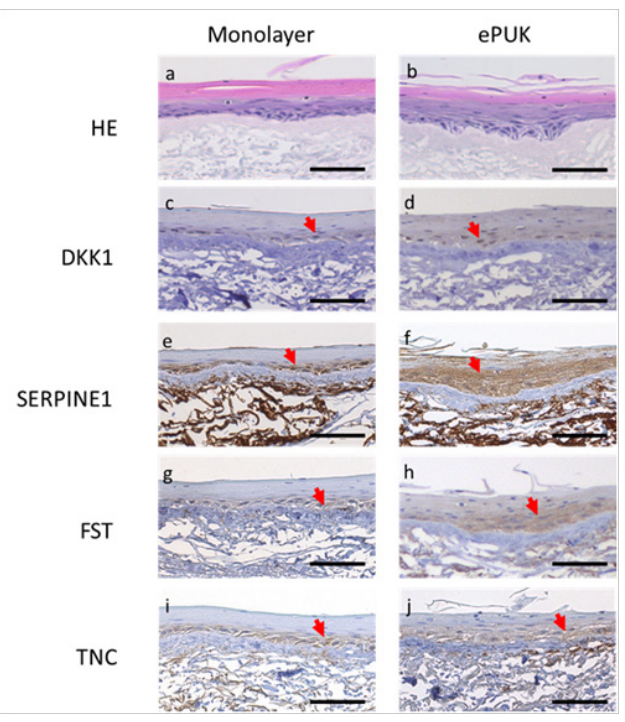

Figure $3 \mathrm{H} \& \mathrm{E}$ and immunohistochemistry of EVPOMEs fabricated by monolayer cells $(a, c, e, g, i)$ and ePUKs $(b, d, f, h, j)$ from the same flask. (a, b) H\&E staining, (c, d) DKKI, (e, f) SERPINEI, (g, h) FST and (i, j) TNC. Scale bar represents $50 \mu \mathrm{m}$. Red arrows indicate positive staining.

\section{Discussion}

EPUKs are grown with two major protocol changes: increased medium volume and more frequent medium changes, and were defined as undifferentiated cells in our previous study. The understanding of a cultured undifferentiated cell population might provide novel insights to tissue engineering where sustaining the cellular capacity of growth, proliferation and mobility is a key to the success of regenerative medicine. ${ }^{11}$ It has been reported that the majority of the ePUKs are a small-sized population, ${ }^{2}$ however, in culture supernatant, large-sized differentiated or dead cells are also floating where they have lost their adherent capacity secondary to their differentiation. Contamination of those large-sized cells cannot be ignored when we analyze the undifferentiated profiles. GACS was successfully used to enrich the population of small-sized undifferentiated cells. ${ }^{4}$ In our results, proteins having higher expression in ePUKs small cells are involved in cellular movement, indicating they might have enhanced ability for wound healing and tissue regeneration. Furthermore, immunohistochemical results showed that the increases in protein expression are seen in EVPOME device, which requires culturing 11days and induction of differentiation. Unlike other proteins, the intensity of tenascin-C expression in ePUKs after fabrication of EVPOME was weakened, indicating it might be affected by the change of culture conditions, which involves a differentiation process and being adherent to the scaffold. Application of ePUKs in regenerative medicine is suggested where expression of those molecules may be beneficial for wound healing after grafting. Further studies including in vivo transplantation are proposed for future tissue engineering use of ePUKs.

Given the present finding among the four proteins validated by western blot, DKK1 specifically inhibits the Wnt/beta-catenin signaling cascade to bind to low-density lipoprotein receptorrelated protein (LRP) 5/6. ${ }^{12}$ Wnt-regulated developmental processes including posterior axial patterning, somitogenesis, angiogenesis, vasculogenesis, and organ formation are implicated in pathological events, including cancer and bone disease. ${ }^{12}$ It also regulates epithelial thickness and senescence in skin and oral mucosa. ${ }^{13,14}$ Follistatin is an antagonist of activin and a subset of TGF $\beta$ super family molecules including myostatin and Bone Morphogenetic Proteins. ${ }^{15}$ Blocking activin action by pre-treatment with its binding protein, follistatin, modifies the inflammatory cytokine cascade, and reduces the severity of the subsequent inflammatory response and mortality. ${ }^{15}$ Limited activation of activin by follistatin in keratinocytes is beneficial for the wound healing process to prevent fibrosis. ${ }^{16}$ SERPINE-1 modulates detachment/re-adhesion cycles involving cellular migration through cell surface receptors including integrin and laminin. ${ }^{17}$ SEPINE-1 expression also correlates with tumor progression, where it is utilized as a cancer marker with poor prognosis. ${ }^{18-22}$ During epithelial would healing, SERPINE-1 is expressed at the wound edge where cell migration is important to achieve wound closure. ${ }^{17}$ Tenascin-C maintains the stem cell niche of the sub ventricular zone of the central nervous system, hematopoietic stem cell niches in bone marrow, corneal limbus and dental pulp. ${ }^{23}$ Regulation of cellular mobility and adherence to interact with fibronectin, integrins and heparin have an important role on wound healing. ${ }^{24-29}$ Interestingly, tenascin-C, DKK1 and follistatin orchestrate the hair follicle development and maintenance of its stem cell niche. ${ }^{30-32}$ High hierarchal progenitor population expressing these markers might be the reservoir of the high proliferative cells investigated in previous ePUKs study. ${ }^{2}$ As a similar concept of ePUKs, Chaffer et al., ${ }^{33}$ identified that populations of human mammary epithelial cells cultured in their normal mammary epithelial growth medium contained a small proportion of cells that grew as floating cells above the majority population of differentiated 
adherent cells can revert to a undifferentiated state, indicating micro environmental signals to entering stem cell state including epithelial-mesenchymal transition may be provoked in those culture conditions. ${ }^{33}$ Another explanation could be cellular competition, which is reported as a phenomenon to exclude different phenotype of the cells both in vivo and in vitro, i.e., transformed cells in early stage of carcinogenesis or to coordinate the patterning and growth of normal tissues during development. ${ }^{34-36}$ In our present study, a heterogenic cell population of primary keratinocytes culture including differentiated cells, proliferating cells, or undifferentiated cells might cause cellular popping. Thus, under the environment of contact inhibition, differentiated keratinocytes may recognize undifferentiated cells as disparate neighbors and extrude undifferentiated cells from their society regulated by the specific signaling pathway, resulting in ePUKs. ${ }^{37}$

Cell death and survival are the most noted molecular and cellular functions in ePUKs small-sized population (Table 1). Most of these proteins are apoptotic induced proteins. Anoikis, the process of cell death, occurs in adherent culture cells when they lose their adherence should be considered here. ${ }^{38,39}$ The majority of the keratinocytes in suspension in ePUKs culture are routinely viable when transferred into a new culture flask, in the conditioned medium, to establish a new culture, ${ }^{2}$ indicating that even up to 24 hours of floating in suspension does not affect their ability to adhere to a new flask surface and be proliferative. However, if the ePUKs cells in suspension are taken out from their original culture environment and re-suspended in fresh growth medium after centrifuging, their plating upon transfer and proliferation rate are lessened, indicating their fragility to changes in the culture environment and centrifuging. ${ }^{2}$ Induced apoptotic proteins in ePUKs small-sized population might be the cause of the mechanical damage seen in cells prior to processing before lysis or passing through the micro pore meshes and centrifuge. Methodological improvements should be considered in future experiments to minimize cell damage.

\section{Conclusion}

In conclusion, the comprehensive proteomics analysis of ePUKs small-sized population is successfully used to identify its specific molecular expression. Our studies suggest that the nutrient state of epithelial cells as well as other physical factors can modulate the expression of proteins possibly involved in the regulation of cellular movement. EVPOMEs made from ePUKs showed the increases in verified protein expression, indicating those are not temporarily expressed during floating status and still represented after induction of differentiation Application of ePUKs in regenerative medicine is suggested since expression of these molecules may be beneficial for wound healing after grafting. Besides the practical application to translational clinical therapies, the ePUKs primary culture can be used in studies to define the control of undifferentiated cells in epithelial tissue wound healing and development.

\section{Acknowledgements}

We thank Dr. Jianhui Zhuand Jintang He for their technical assistance and critical comments and Kristina Fields for her technical assistance of immunohistochemistry. We also acknowledge the National Institutes of Health under grant R01GM49500 (DML) and USA Department of Defense Grant to AFIRM I: W81XWH-08-2-0034 (SEF) for support of this work.

\section{Conflict of interest}

The author declares no conflict of interest.

\section{References}

1. Izumi K, Kato H, Feinberg SE. 3D reconstruction of oral mucosa; Tissue engineering strategies. In: Vishwakarma A, et al. editors. Stem Cell Biology and Tissue Engineering in Dental Science. USA: Academic Press/Elsevier; 2014. p. 721-731.

2. Marcelo CL, Peramo A, Ambati A, et al. Characterization of a unique technique for culturing primary adult human epithelial progenitor/"stem cells. BMC Dermatol. 2012;12:8

3. Peramo A, Feinberg SE, Marcelo CL. Characterization of cultured epithelial cells using a novel technique not requiring enzymatic digestion for sub culturing. Cell Tissue Bank. 2013;14(3):423-435.

4. Izumi K, Tobita T, Feinberg SE. Isolation of human oral keratinocyte progenitor/stem cells. J Dent Res. 2007;86(4):341-346.

5. Fujimori Y, Izumi K, Feinberg SE, et al. Isolation of small-sized human epidermal progenitor/stem cells by Gravity Assisted Cell Sorting (GACS). J Dermatol Sci. 2009;56(3):181-187.

6. Izumi K, Marcelo CL, Feinberg SE. Enrichment of oral mucosa and skin keratinocyte progenitor/stem cells. Methods Mol Biol. 2013;989:293303.

7. Kato H, Izumi K, Saito T, et al. Distinct expression patterns and roles of aldehyde dehydrogenases in normal oral mucosa keratinocytes: Differential inhibitory effects of a pharmacological inhibitor and RNAimediated knockdown on cellular phenotype and epithelial morphology. Histochem Cell Biol. 2013;139(6):847-862.

8. Zhu J, Nie S, Wu J, et al. Target proteomic profiling of frozen pancreatic CD24+ adenocarcinoma tissues by immuno-laser capture microdissection and nano-LC-MS/MS. J Proteome Res. 2013;12(6):2791-2804.

9. Brancolini C. Dismantling Cell-Cell Contacts during Apoptosis Is Coupled to a Caspase-dependent Proteolytic Cleavage of beta-Catenin. J Cell Biol. 1997;139:759-771.

10. Gérard C, Goldbeter A. The balance between cell cycle arrest and cell proliferation: control by the extracellular matrix and by contact inhibition. Interface Focus. 2014;4(3):20130075.

11. Markeson D, Pleat JM, Sharpe JR, et al. Scarring, stem cells, scaffolds and skin repair. J Tissue Eng Regen Med. 2015;9(6):649-668.

12. Cruciat CM, Niehrs C. Secreted and transmembrane wnt inhibitors and activators. Cold Spring Harb Perspect Biol. 2013;5(3):a015081.

13. Yamaguchi Y, Passeron T, Hoashi T, et al. Dickkopf 1 (DKK1) regulates skin pigmentation and thickness by affecting Wnt/beta-catenin signaling in keratinocytes. FASEB J. 2008;22(4):1009-1020.

14. Zhao J, Kim KA, De Vera J, et al. R-Spondin1 protects mice from chemotherapy or radiation-induced oral mucositis through the canonical Wnt/beta-catenin pathway. Proc Natl Acad Sci USA. 2009;106(7):23312336 .

15. deKretser DM, O'Hehir RE, Hardy CL, et al. The roles of activin A and its binding protein, follistatin, in inflammation and tissue repair. $\mathrm{Mol}$ Cell Endocrinol. 2012;359(1-2):101-106.

16. Antsiferova M, Klatte JE, Bodó E, et al. Keratinocyte-derived follistatin regulates epidermal homeostasis and wound repair. Lab Invest. 2009;89(2):131-141

17. Czekay RP, Wilkins-Port CE, Higgins SP, et al. PAI-1:An Integrator of Cell Signaling and Migration. Int J Cell Biol. 2011;2011:562481.

18. Lee CC, Huang TS. Plasminogen activator inhibitor-1: the expression, biological functions, and effects on tumorigenesis and tumor cell adhesion and migration. J Cancer Mol. 2005;1(1):25-36.

19. Providence KM, Higgins PJ. PAI-1 expression is required for epithelial cell migration in two distinct phases of in vitro wound repair. $J$ Cell Physiol. 2004;200(2):297-308. 
20. Freytag J, Wilkins-Port CE, Higgins CE, et al. PAI-1 Regulates the Invasive Phenotype in Human Cutaneous Squamous Cell Carcinoma. $J$ Oncol. 2009;2009:963209.

21. Cheng CF, Fan J, Bandyopahdhay B, et al. Profiling motility signalspecific genes in primary human keratinocytes. J Invest Dermatol. 2008;128(8):1981-1990.

22. Hundsdorfer B, Zeilhofer HF, Bock KP, et al. Tumour-associated urokinase-type plasminogen activator (uPA) and its inhibitor PAI-1 in normal and neoplastic tissues of patients with squamous cell cancer of the oral cavity - clinical relevance and prognostic value. J Craniomaxillofac Surg. 2005;33(33):191-196.

23. Chiquet-Ehrismann R, Orend G, Chiquet M, et al. Tenascins in stem cell niches. Matrix Biol. 2014;37:112-123.

24. Hauzenberger D, Olivier P, Gundersen D, et al. Tenascin-C inhibits beta1 integrin-dependent $\mathrm{T}$ lymphocyte adhesion to fibronectin through the binding of its fnIII 1-5 repeats to fibronectin. Eur J Immunol. 1999;29(5):1435-1447.

25. Sriramarao P, Mendler M, Bourdon MA. Endothelial cell attachment and spreading on human tenascin is mediated by integrins. $J$ Cell Sci 1993;105(pt 4):1001-1012.

26. Schnapp LM, Hatch N, Ramos DM, et al. The Human Integrin alpha 8 beta 1 Functions as a Receptor for Tenascin, Fibronectin, and Vitronectin. J Biol Chem. 1995;270(39):23196-23202.

27. Yokosaki Y, Palmer EL, Prieto AL, et al. The integrin alpha 9 beta 1 mediates cell attachment to a non-RGD site in the third fibronectin type III repeat of tenascin. J Biol Chem. 1994;269:26691-26696.

28. Aukhilt I, Yant Y, Aukhil I, et al. Cell- and heparin-binding domains of the hexabrachion arm identified by tenascin expression proteins. $J$ Biol Chem. 1993;268(4):2542-2553.

29. Itoh S, Yamaoka N, Kamoshida G, et al. Staphylococcal superantigenlike protein 8 (SSL8) binds to tenascin $\mathrm{C}$ and inhibits tenascin $\mathrm{C}$ fibronectin interaction and cell motility of keratinocytes. Biochem Biophys Res Commun. 2013;433(1):127-132.
30. Nakamura M, Matzuk MM, Gerstmayer B, et al. Control of pelage hair follicle development and cycling by complex interactions between follistatin and activin. FASEB J. 2003;17(30):497-499.

31. Chen CC, Murray PJ, Jiang TX, et al. Regenerative hair waves in aging mice and extra-follicular modulators follistatin, dkk1, and sfrp4. J Invest Dermatol. 2014;134(8):2086-2096.

32. Hsu YC, Li L, Fuchs E. Emerging interactions between skin stem cells and their niches. Nat Med. 2014;20(8):847-856.

33. Chaffer CL, Brueckmann I, Scheel C, et al. Normal and neoplastic nonstem cells can spontaneously convert to a stem-like state. Proc Nat Acad Sci U S A. 2011;108(19):7950-7955.

34. Hogan C, Kajita M, Lawrenson K, et al. Interactions between normal and transformed epithelial cells: Their contributions to tumourigenesis. Int J Biochem Cell Biol. 2011;43(4):496-503.

35. Yamauchi H, Fujita Y. Epithelial self-defense against cancer. Cell Res. 2012;22(110):1527-1529.

36. Amoyel M, Bach E. Cell competition:how to eliminate your neighbours. Development. 2014;141(5):988-1000

37. Zhao B, Tumaneng K, Guan KL. The Hippo pathway in organ size control, tissue regeneration and stem cell self-renewal. Nat Cell Biol. 2011;13(8):877-883

38. Banno T, Blumenberg M. Keratinocyte Detachment-Differentiation Connection Revisited, or Anoikis-Pityriasi Nexus Redux. PLoS One. 2014;9(6):e100279.

39. Grossmann J. Molecular mechanisms of "detachment-induced apoptosis-Anoikis". Apoptosis. 2002;7(3):247-260. 